\title{
Synthesis of Silica Powder from Sugar Cane Bagasse Ash and Its Application as Adsorbent in Adsorptive-distillation of Ethanol-water Solution
}

\author{
Megawati ${ }^{a}$, Dewi Selvia Fardhyanti, Radenrara Dewi Artanti Putri, Oki Fianti, Agustin Fitrianingsi \\ Simalango and Afiati Estrina Akhir \\ Department of Chemical Engineering, Faculty of Engineering, Universitas Negeri Semarang, Indonesia
}

\begin{abstract}
In this study, sugarcane bagasse ash (SCBA) as waste from sugarcane factory was extracted into silica powder. This powder was then used as adsorbent for ethanol purification. Prior to used, the SCBA was washed using $\mathrm{HCl}$ solution. The silica extraction was conducted using various $\mathrm{NaOH}$ concentrations $(0.5 ; 1 ; 1.5$ and $2 \mathrm{~mol} / \mathrm{L})$ as well as extraction times $(30,60$ and 90 minutes). After that the mixture was precipitated using $\mathrm{HCl}$ solution. The solution was filtrated through a paper filter and its solid particle was dried until its weight was constant. The particle was grounded and sieved using 18 mesh sieves. The silica powder obtained was analysed using FTIR and its result showed that the powder has silica functional groups. The silica yield increases with increasing of concentration of $\mathrm{NaOH}$ solution as well as extraction time. The highest silica yield $(45.5 \% \mathrm{w} / \mathrm{w})$ was achieved at $2 \mathrm{~mol} / \mathrm{L} \mathrm{NaOH}$ solution at $90 \mathrm{~min}$. The surface area, pore diameter, and pore volume of silica powder were measured to be 407 $\mathrm{m}^{2} / \mathrm{g}, 3.81 \AA$, and $2.76 \mathrm{dm}^{3} / \mathrm{g}$, respectively. From application of silica powder as adsorbent in adsorptive-distillation, ethanol concentration can reach $99.3 \% \mathrm{w} / \mathrm{w}$ which indicates azeotropic point can be passed.
\end{abstract}

\section{Introduction}

A sugarcane factory produces sugarcane bagasse ash (SCBA) as by-product. Indonesia's sugarcane production reaches 2.6 tonnes in 2015 [1]. Generally about $280 \mathrm{~kg}$ wet bagasse is produced from 1 tonne of cane processed [2]. In addition, sugarcane bagasse used as boiler fuel will result in SCBA as waste $(8-10 \% \mathrm{w} / \mathrm{w})$. SCBA has high silica content $(53.1 \% \mathrm{w} / \mathrm{w})[3,4]$. The silica extraction process will produce silica crystal that can be used as hydrophilic adsorbent with surface area between 200$800 \mathrm{~m}^{2} / \mathrm{g}$ [5]. The silica powder production process is performed through major steps: raw material preparation, silica extraction, and silica precipitation [6]. The operation condition to obtain the highest silica yield is at $600^{\circ} \mathrm{C}, 3$ hours, and using $91.57 \% \mathrm{HCl}$ solution $[7,8]$.

At $10 \% \mathrm{v} / \mathrm{v}$ solvent concentration, the silica yielded from rice husk extracted using $1 \mathrm{~mol} / \mathrm{L} \mathrm{KOH}$ and $\mathrm{NaOH}$ solutions as solvent were about 10.80 and $22.59 \% \mathrm{w} / \mathrm{w}$, respectively. Thus, this study was carried out using $\mathrm{NaOH}$ solution at various concentrations $(0.5 ; 1 ; 1.5$ and $2 \mathrm{~mol} / \mathrm{L})$. Theoretically the solvent concentration increasing increase silica yield as well as $\mathrm{HCl}$ solution at $\mathrm{pH} 7$ can be used to

\footnotetext{
${ }^{\mathrm{a}}$ Corresponding author : megawati@mail.unnes.ac.id
} 
precipitate silica after silica extraction [9]. The silica precipitation had been performed using $\mathrm{HCl}$ solution at various $\mathrm{pH}(1,3,5,7)$ and at $\mathrm{pH} 7$ produced the highest yield $(91 \% \mathrm{w} / \mathrm{w})$ [10].

Accordingly, silica powder can be used as adsorbent in adsorptive-distillation to break azeotropic point of ethanol-water solution for ethanol purification. The polar bond of silica powder works very well to remove water content in ethanol-water solution. Silica powder has $4 \AA$ pore diameter so it can be used to adsorb water with $2.8 \AA$ pore diameter and entrance ethanol with $4.4 \AA$ pore diameter [11]. Adsorptive-distillation for ethanol purification was performed and obtained the highest ethanol concentration using white and blue silica gels as adsorbent at 96.67 and $95.662 \% \mathrm{v} / \mathrm{v}$, respectively [12]. In this study, the silica powder obtained was applied as adsorbents in adsorptive-distillation of ethanol-water solution.

\section{Research methodology}

The SCBA used in this research was obtained from sugar company (PT Madubaru, Yogyakarta). Prior to silica extraction, SCBA was heated using furnace for $3 \mathrm{~h}$ at $600^{\circ} \mathrm{C}$ to eliminate carbon content. The ash then was washed with $1 \mathrm{~mol} / \mathrm{L} \mathrm{HCl}$ solution to remove minerals such as extractive mineral and iron composition. The washed products were filtered with filter paper and the filtered solid was stored in a glass bottle. The SCBA before and after washing was analysed using X-Ray Fluorescence (XRF) at Central Laboratory of Mineral and Material Advanced FMIPA, Universitas Negeri Malang.

In silica extraction, $10 \mathrm{~g} \mathrm{SCBA}$ was extracted using $100 \mathrm{~mL} \mathrm{NaOH}$ solution to alter the chemical and physical structures. The extraction was conducted in a two-neck flask and heated using a hot plate at $100^{\circ} \mathrm{C}$ for specific time and stirred using a $200 \mathrm{rpm}$ magnetic stirrer. After that, the mixture was cooled and filtered in order to remove solid residues. The filtrate of sodium silicate was precipitated using $1 \mathrm{~mol} / \mathrm{L} \mathrm{HCl}$ solution until $\mathrm{pH} 7$ and kept for at least 18 hours at room temperature for silica to completely solidified. The slurry then was filtered and washed with distilled water repeatedly until reached neutral $\mathrm{pH}$. The solid was dried using oven at $80^{\circ} \mathrm{C}$, grounded and then sieved. In this research, the process variable was $\mathrm{NaOH}$ concentrations $(0.5 ; 1 ; 1.5$ and $2 \mathrm{~mol} / \mathrm{L})$ as well as extraction times (30,60, and 90 minutes). The silica powder produced was tested for characteristics of functional groups and surface area $\left(\mathrm{m}^{2} / \mathrm{g}\right)$, pore diameter $(\AA)$, and pore volume $\left(\mathrm{cm}^{3} / \mathrm{g}\right)$ using Fourier Transform Infrared (FTIR) spectroscopy Perkin Elmer Spectrum Version 10.03. 06 and Brunauer, Emmet, Teller (BET) Quantachrome Nova 1200e.

The adsorptive-distillation of ethanol-water solution using $10 \mathrm{~g}$ silica powder produced in this research was conducted in a batch distillation completed with $10 \mathrm{~cm}$ adsorbent column. The $100 \mathrm{~mL}$ $96 \% \mathrm{w} / \mathrm{w}$ initial ethanol was boiled in three-neck bottle by a heating mantle at $80^{\circ} \mathrm{C}$. The vapor flowed to adsorbent in column connected to condenser. The condensate density was analyzed using a picnometer. After that its ethanol content is calculated.

\section{Results and discussion}

The SCBA from PT Madubaru Yogyakarta was heated in furnace to remove carbon compound [9]. SCBA colour is different after heated in furnace. Before SCBA was heated, it was black and after heating turned to light brown (Figure 1). The heated SCBA was then washed using $\mathrm{HCl}$ solution to remove minerals, so that silica composition increases $[3,13]$. Both SCBA before and after washed were analyzed by X-Ray Fluorescence (XRF), as in Table 1. The major component in SCBA before washing was $\mathrm{Si}$ with $40.2 \% \mathrm{w} / \mathrm{w}$ and after washing became $54 \% \mathrm{w} / \mathrm{w}$. It obvious that raw material is suitable to be used as source of silica for producing silica powder. The amount of phosphor, chromium, manganese, nickel, copper, barium, and rhenium decreased from about 7.41 to $5.10 \% \mathrm{w} / \mathrm{w}$. In addition, calcium content can be reduced from 15.7 to $7.12 \% \mathrm{w} / \mathrm{w}$ but potassium and ferric contents cannot be reduced significantly. This fact suggests that SCGA washing using various $\mathrm{HCl}$ concentrations should be applied to achieve minimum contents of impurities. 


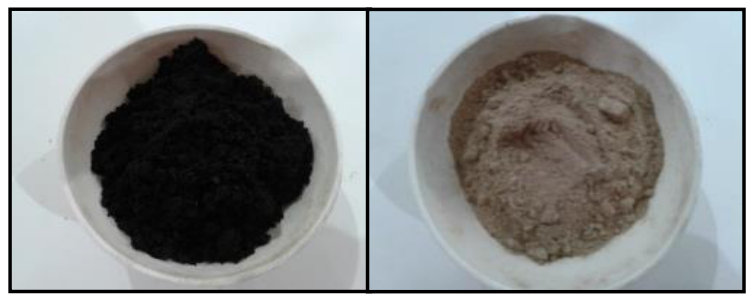

(a)

(b)

Figure 1. (a) Before heated in furnace and (b) After heated in furnace.

Table 1. Composition of sugarcane bagasse ash (SCBA).

\begin{tabular}{|c|c|c|}
\hline Composition & \multicolumn{2}{|c|}{ Concentration (\% w/w) } \\
\hline $\mathrm{Si}$ & $\begin{array}{c}\text { Before washed with } \\
\text { HCl solution }\end{array}$ & $\begin{array}{c}\text { After washed with } \\
\text { HCl solution }\end{array}$ \\
\hline $\mathrm{P}$ & 40.2 & 54.0 \\
\hline $\mathrm{K}$ & 1.40 & 0.00 \\
\hline $\mathrm{Ca}$ & 9.40 & 8.49 \\
\hline $\mathrm{Cr}$ & 15.7 & 7.12 \\
\hline $\mathrm{Mn}$ & 0.11 & 0.10 \\
\hline $\mathrm{Fe}$ & 1.10 & 0.79 \\
\hline $\mathrm{Ni}$ & 24.8 & 23.2 \\
\hline $\mathrm{Cu}$ & 3.90 & 3.27 \\
\hline $\mathrm{Ba}$ & 0.66 & 0.55 \\
\hline $\mathrm{Re}$ & 0.30 & 0.10 \\
\hline
\end{tabular}

The silica extraction process was conducted using $\mathrm{NaOH}$ solution and then precipitated using $\mathrm{HCl}$ solution, adapting from the literature [14]. These mechanisms can be expressed by Equations 1 and 2 [15]. At the end of these steps, the slurry was filtered and filtered solid was heated in oven. Several photos for these steps show as in Figure 2.

$$
\begin{aligned}
& 2 \mathrm{NaOH}+\mathrm{SiO}_{2}(\text { in } \mathrm{SCGA}) \text {----> } \mathrm{Na}_{2} \mathrm{SiO}_{3}+\mathrm{H}_{2} \mathrm{O} \\
& \mathrm{Na} 2 \mathrm{SiO} 3+2 \mathrm{HCl}---->\mathrm{SiO}_{2} \text { (pure silica powder) }+\mathrm{H}_{2} \mathrm{O}
\end{aligned}
$$

The influence of $\mathrm{NaOH}$ concentration to silica yield can be seen in Table 2. The most silica yield $(45.5 \% \mathrm{w} / \mathrm{w})$ was obtained from synthesis with $2 \mathrm{~mol} / \mathrm{L} \mathrm{NaOH}$ solution for $90 \mathrm{~min}$. The production of silica tends to increase in line with $\mathrm{NaOH}$ concentration $(0.5$ to $2 \mathrm{~mol} / \mathrm{L})$ at all extraction times tested in this study. This phenomenon is similar to previous research [9]. Figure 3 presents the FTIR spectrum of silica powder, where the presence of three main bands of silica is observed; at 3835.75 and $1638.15 \mathrm{~cm}^{-1}$, the bands correlate with $\mathrm{Si}-\mathrm{OH}$, the bands at 1099.21 to $799.62 \mathrm{~cm}^{-1}$ is assigned to $\mathrm{Si}-\mathrm{O}-\mathrm{Si}$, and that at $474.80 \mathrm{~cm}^{-1}$ is due to O-Si-O (Table 3). Accordingly, the main bands of silica were O-Si-O, O-H, and Si-O-Si with the peaks around 438, 796, and $1044 \mathrm{~cm}^{-1}$, respectively [13]. 
However, other research shows that the silica produced had the bands of Si-O-Si, O-Si-O, and Si-OH with wavenumbers of 1077,464 , and $1644 \mathrm{~cm}^{-1}$ [16]. Subsequently, the main bands of silica powder produced from this study was similar to previous research.

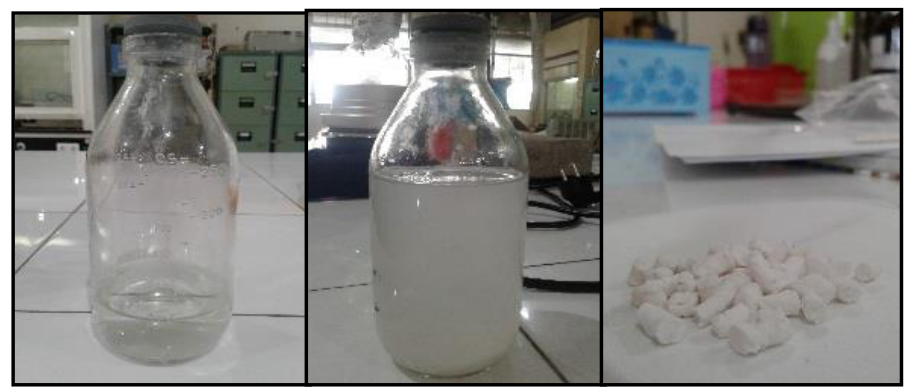

Figure 2. Silica precipitation (Process condition: washed with $1 \mathrm{~mol} / \mathrm{L} \mathrm{HCl}$ solution, extracted with $1 \mathrm{~mol} / \mathrm{L}$ $\mathrm{NaOH}$, ratio of SCBA: $\mathrm{NaOH}=1: 10 \mathrm{w} / \mathrm{v}$, volume $=100 \mathrm{~mL}$; precipitated with $1 \mathrm{~mol} / \mathrm{L} \mathrm{HCl}$ solution).

Table 2. Silica yield of sugarcane bagasse ash (SCBA) extraction using $\mathrm{NaOH}$ solution.

\begin{tabular}{|c|c|c|c|}
\hline NaOH Concentration & \multicolumn{3}{|c|}{ Silica Yield (\% w/w) } \\
\hline & $30 \mathrm{~min}$ & $60 \mathrm{~min}$ & $90 \mathrm{~min}$ \\
\hline 0.5 & 10.6 & 14.0 & 14.1 \\
\hline 1.0 & 13.0 & 24.1 & 25.1 \\
\hline 1.5 & 25.4 & 35.7 & 35.8 \\
\hline 2.0 & 26.2 & 45.3 & 45.5 \\
\hline
\end{tabular}

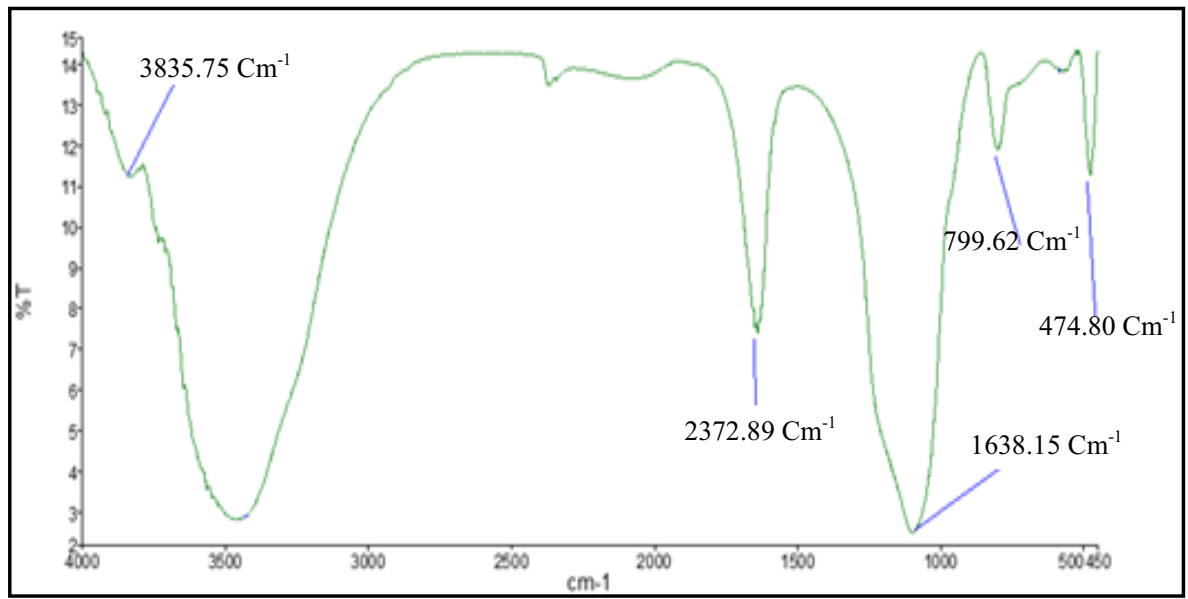

Figure 3. Fourier Transform Infrared (FTIR) of silica powder of sugarcane bagasse ash (SCBA) extraction using $\mathrm{NaOH}$ Solution.

Analysis of silica powder using Brunauer, Emmet, Teller (BET) to know powder's characteristics resulted a surface area $407 \mathrm{~m}^{2} / \mathrm{g}$, pore diameter $3.806 \AA$, and pore volume $0.276 .10^{-2} \mathrm{~cm}^{3} / \mathrm{g}$. Based on previous research, silica crystal has surface area $218 \mathrm{~m}^{2} / \mathrm{g}$, pore diameter $5.56 \AA$, and pore volume $0.32 .10^{-2} \mathrm{~cm}^{3} / \mathrm{g}$ [13]. Moreover, from other research, silica crystal has surface area $265 \mathrm{~m}^{2} / \mathrm{g}$, pore diameter $6.25 \AA$, and pore volume $0.425 .10^{-2} \mathrm{~cm}^{3} / \mathrm{g}$ [17]. The comparison indicates that silica powder 
produced in this research has physical characteristic as same as with previous research. In text book, surface area of silica crystal is about $200-800 \mathrm{~m}^{2} / \mathrm{g}[5]$.

Table 3. The Wavenumber and main bands of silica powder from sugarcane bagasse ssh (SCBA) extraction using $\mathrm{NaOH}$ solution.

\begin{tabular}{|c|c|c|}
\hline No & Wavenumber $\left(\mathbf{c m}^{-\mathbf{1}}\right)$ & Band \\
\hline 1 & 3835,75 & Si-OH \\
\hline 2 & 1638,15 & Si-OH \\
\hline 3 & 1099.21 & Si-O-Si \\
\hline 4 & 799.620 & Si-O-Si \\
\hline 5 & 474.800 & O-Si-O \\
\hline
\end{tabular}

In this study, the silica powder produced was applied as adsorbent of water vapor in adsorptivedistillation of ethanol-water solution in order to increase the ethanol concentration. The adsorption capacity of silica powder will increase if the silica was heated prior to use. Before silica was heated, the capacity was just $0.02 \%$, but after heating, the capacity increased up to $3.2 \%$. Subsequently, ethanol concentration increased from $96 \% \mathrm{v} / \mathrm{v}$ to $99,3 \% \mathrm{v} / \mathrm{v}$. This condition shows that azeotropic point of ethanol-water solution is passed. Hence, continuous distillation to obtain absolute concentration can be conducted using simple distillation.

\section{Conclusions}

Silica powder was successfully extracted from sugarcane bagasse ash conducted by a heating process followed extraction with $\mathrm{NaOH}$ solution and precipitation with $\mathrm{HCl}$ solution. XRF analysis showed SCBA composition data indicating that $\mathrm{Si}$ content was about $54 \% \mathrm{w} / \mathrm{w}$ after heating and washing. The production of silica tends to increase in line with $\mathrm{NaOH}$ concentration $(0.5$ to $2 \mathrm{~mol} / \mathrm{L})$. The most silica yield $(45.5 \% \mathrm{w} / \mathrm{w})$ was obtained from synthesis process using $2 \mathrm{~mol} / \mathrm{L} \mathrm{NaOH}$ solution for 90 min. Based on BET analysis, the silica powder has characteristics such as surface area $407 \mathrm{~m}^{2} / \mathrm{g}$, pore diameter $3.806 \AA$, and pore volume $0.276 .10^{-2} \mathrm{~cm}^{3} / \mathrm{g}$. Furthermore, the application of silica powder as adsorbent showed significant increase of ethanol concentration, from 96 to $99.3 \% \mathrm{v} / \mathrm{v}$.

\section{References}

1. Badan Pusat Statistika, Statistik Tebu Indonesia (Badan Pusat Statistika, Jakarta, 2015)

2. S. Yokoyama, Buku Panduan Untuk Produksi dan Pemanfaatan Biomassa (The Japan Institut of Energy, Tokyo, 2008)

3. S. Norsuraya, H. Fazlena, R. Norhasyimi, Proceedia Eng. E 148 (2016)

4. S. Rovani, J.J. Santos, P. Corio, D.A. Fungaro, ACS Omega E 3 (2018)

5. K. Othmer, Encyclopedia of Chemical Technology (Wiley-Interscience, New York, 1997)

6. V. Hariharan, G. Sivakumar, I. J. of Chem. Tech. Res. E 5, 3 (2013)

7. V. B. Carmona, R. M. Oliveira, W. T. L. Silva, Ind. Crops and Products E 42, 1 (2013)

8. P. Worathanakul, W. Payubnob, A. Muangpet, I. J. Chem. Molecul. Nuclear, Mat. and Metallurgical Eng. E 3, 8 (2009)

9. M. Soleh, Ekstraksi Silika dari Sekam Padi dengan Metode Pelarutan dan Pengendapan Silika serta Analisis EDX dan FTIR. Thesis (Institut Pertanian Bogor, Bogor, 2014)

10. U. Kalapathy, A. Proctor, J. Shultz, Bioresour. Technol. E 73 (2000) 
11. H. J. Huang, S. Ramaswamy, U. W. Tschimer, B. V. Ramarao, Separation and Purification Technology (Woodhead Publishing, 2008)

12. Megawati, R. A. Jannah, I. Rahayuningtyas, AIP Conference Proceeding E 1788 (2017)

13. R. A. Bakar, R. Yahya, S. N. Gan, Proceedia Chem. E 19 (2016)

14. P. A. Handayani, E. Nurjanah, W. D. P. Rengga, Jurnal Bahan Alam Terbarukan E 4, 2 (2014)

15. B. S. Todkar. O. A. Deorukhkar, S. M. Deshmukh, I. J. of Eng. Res. and Dev. E 12, 3 (2016)

16. A. Tadjarodi, M. Haghverdi, V. Mohammadi, Mat. Res. Bulletin E 47 (2012)

17. R. H. Alves, T. V da S. Reis, S. Rovani, D. A. Fungaro, J. of Chem. E 1-9 (2017) 